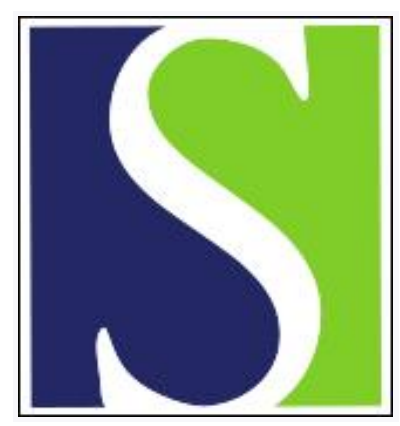

Scand J Work Environ Health 2010;36(1):1-2

https://doi.org/10.5271/sjweh.2882

Published online: 07 Dec 2009, Issue date: 00 Jan 2010

The role of assessment of biomechanical exposure at the workplace in the prevention of musculoskeletal disorders by Burdorf $A$

Affiliation: Department of Public Health, Erasmus Medical Center, 3000 CA Rotterdam, The Netherlands. a.burdorf@erasmusmc.nl

Refers to the following texts of the Journal: 2001;27(2):125-132

2010;36(1):3-24 2009;35(4):245-260 2001;27 suppl 2:1-52

2009;35(1):56-64 2008;34(6):420-429 2009;35(4):301-308

2008;34(2):120-132 2009;35(2):134-144 2009;35(1):19-36

The following article refers to this text: $2014 ; 40(3): 278-286$

Key terms: assessment; biomechanical exposure; editorial; exposure; MSD; musculoskeletal disorder; prevention; workplace

This article in PubMed: www.ncbi.nlm.nih.gov/pubmed/19967327

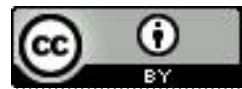




\section{The role of assessment of biomechanical exposure at the workplace in the prevention of musculoskeletal disorders}

Musculoskeletal disorders constitute an important part of the work-related burden of disease (1). Various components of biomechanical exposure at the workplace play a prominent role in the onset and aggravation of musculoskeletal disorders. Recent publications in the Scandinavian Journal of Work, Environment \& Health have addressed physical risk factors for specific musculoskeletal disorders (2, 3), and subsequent consequences for productivity loss at work $(4,5)$, sickness absence $(6)$, and disability $(7)$. Despite this knowledge, however, it is still difficult to quantify the exact levels of biomechanical exposure at which an increase in the occurrence of musculoskeletal disorders occurs. This has hampered our ability to recommend acceptable levels of biomechanical exposure at work (8), whereas for chemical agents many threshold limit values are available that guide the occupational health professional in the prevention of work-related diseases. Primary preventive interventions to reduce biomechanical exposure at work have difficulties in demonstrating that a reduction in biomechanical exposure results in a lower occurrence of musculoskeletal disorders $(9,10)$. The assessment of biomechanical exposure has emerged as a key issue in developing guidelines to prevent the onset of musculoskeletal disorders in occupational populations and designing appropriate primary preventive interventions that reduce hazardous biomechanical exposure to levels that no longer harm the workforce.

The most widely used method of assessing physical load during work is still the self-administered questionnaire, mainly because data collection costs are low, application is feasible in every study design, a large array of different parameters of exposure can be determined simultaneously, and all risk factors are assessed with a similar approach (11). However, the validity of self-reported biomechanical exposure is low and most measures of exposure lack sufficient precision and accuracy to present valid estimates of the mean level of biomechanical exposure in occupational groups. Hence, the exposure information is too crude to derive exposure guidelines or evaluate the success of preventive interventions. At best, welldesigned questionnaires are able to identify relative differences in exposure among occupational groups and, hence, rank these groups according to their overall level of biomechanical exposure at work.

In recent years several observational methods have been developed to assess biomechanical exposure at the workplace. In this issue of the Scandinavian Journal of Work, Environment \& Health, Takala and colleagues present a systematic evaluation of these observational methods (12). A total of 30 observational methods were identified that evaluate biomechanical hazards at work, monitor the effects of ergonomic improvements, and enable research on exposure-response relationships. These methods are capable of simultaneously assessing different awkward postures, strenuous movements, and manual materials handling in various work situations. The comprehensive evaluation showed that 19 out of 30 observational methods had moderate-to-good agreement with direct measurements from video recordings. Agreement was better for large-scale body postures and work actions, such as trunk flexion, squatting, kneeling, and lifting activities. Micropostures like wrist and hand movements as well as neck and trunk rotation were more difficult to assess with reasonably accuracy. In observational methods, a lack of precision may arise from intra- and inter-observer variance, but overall repeatability, when evaluated, was moderate to good.

An interesting conclusion of the review was that very few publications on observational methods present any insight into the appropriate exposure assessment strategy. The choice for a particular observational method not only depends on its validity and repeatability, but also on its feasibility to describe exposure patterns in the study population with sufficient detail on frequency, duration, and magnitude of relevant parameters of exposure, taking into account the variation in exposure within and between workers 
and across determinants of biomechanical exposure. In any study, crucial decisions must be made about how to allocate best the measurement efforts across individual workers, work situations, and work days, taking into account the performance of the observational method chosen, the required discriminatory power, and variation in parameters of biomechanical exposure. In intervention studies, these decisions will determine whether the application of an observational method will be able to demonstrate a significant impact of an ergonomic improvement. Commonly adopted strategies often fail to detect an intervention's effect on the overall biomechanical exposure in some jobs due to the fact that too few measurements have been collected. It has been shown that, even for large differences in biomechanical exposure, a substantial number of measurements is required (13) and that limited exposure sampling may result in a low probability of detecting any intervention effect at all (14).

The importance of Takala et al's review is the guidance it offers to researchers and occupational health professionals in selecting the best method in relation to the study to be conducted. The authors' recommendations provide good advice on the initial selection of the most appropriate observational method for biomechanical exposure and design of the sampling strategy in order to provide productive results. There is a clear need for better quantification of biomechanical exposure at work and observational methods may play an important role in this endeavor. Researchers and professionals are challenged to adopt these methods to design and implement appropriate primary preventive interventions on hazardous biomechanical exposure in order to reduce the high burden of disease due to work-related musculoskeletal disorders.

\section{References}

1. Punnett L, Prüss-Ütün A, Nelson DI, Fingerhut MA, Leigh J, Tak SW, et al. Estimating the global burden of low back pain attributable to combined occupational exposures. Am J Ind Med. 2005;48:459-69.

2. Rijn van RM, Huisstede BMA, Koes BW, Burdorf A. Associations between work-related factors and carpal tunnel syndrome: a systematic review. Scand J Work Environ Health. 2009;35(1):19-36.

3. Lapointe J, Dionne CE, Brisson C, Montreuil S. Interaction between postural risk factors and job strain on self-reported musculoskeletal symptoms among users of video display units: a three-year prospective study. Scand J Work Environ Health. 2009;35(2):134-44.

4. Boström M, Dellve L, Thomée S, Hagberg M. Risk factors for generally reduced productivity - a prospective cohort study of young adults with neck or upper-extremity musculoskeletal symptoms. Scand J Work Environ Health. 2008;34(2):120-32.

5. Martimo KP, Shiri R, Miranda H, Ketola R, Varonen H, Viikari-Juntura E. Self-reported productivity loss among workers with upper-extremity disorders. Scand J Work Environ Health 2009;35(4):301-8.

6. Geuskens GA, Hazes JMW, Barendregt PJ, Burdorf A. Predictors of sick leave and reduced productivity at work among persons with early inflammatory joint conditions. Scand J Work Environ Health. 2008;34(6):420-9.

7. Welch L, Haile E, Boden LI, Hunting KL. Musculoskeletal disorders among construction roofers - physical function and disability. Scand J Work Environ Health. 2009;35(1):56-63.

8. Fallentin N, Viikari-Juntura E, Waersted M, Kilbom Å. Evaluation of physical workload standards and guidelines from a Nordic perspective. Scand J Work Environ Health. 2001;27 suppl 2:1-52.

9. Lötters F, Burdorf A. Are changes in mechanical exposure and musculoskeletal health good performance indicators for primary prevention. Int Arch Occup Environ Health. 2002;75:549-61.

10. Dempsey PG. Effectiveness of ergonomics interventions to prevent musculoskeletal disorders: beware of what you ask. Int J Ind Ergon. 2007;37:169-73.

11. Barrero LH, Katz JN, Dennerlein JT. Validity of self-reported mechanical demands for occupational epidemiologic research of musculoskeletal disorders [review]. Scand J Work Environ Health. 2009;35(4):245-60.

12. Takala EP, Pehkonen I, Forsman M, Hansson GA, Mathiassen SE, Neumann WP, et al. Systematic evaluation of observational methods assessing biomechanical exposures at work [review]. Scand J Work Environ Health. 2010;36(1):3-24.

13. Mathiassen SE, Paquet V. The ability of limited exposure sampling to detect effects of interventions that reduce the occurrence of pronounced trunk inclination. Appl Ergon. 2010;41:295-304.

14. Hoozemans MJM, Burdorf A, Beek van der A, Frings-Dresen MHW, Mathiassen SE. Group-based measurement strategies in exposure assessment explored by bootstrapping. Scand J Work Environ Health. 2001;27(2):125-32.

Alex Burdorf

Department of Public Health, Erasmus Medical Center

PO Box 2040

3000 CA Rotterdam, The Netherlands

[E-mail: a.burdorf@erasmusmc.nl] 